\title{
EROSION RISK MAPPING USING RUSLE WITH GIS: CASE STUDY OF BÜYÜK MENDERES RIVER BASIN OF TURKEY
}

\author{
M.A. ERDOĞAN ${ }^{1}$, H. ESBAH ${ }^{2} \&$ S. BERBEROGLU ${ }^{1}$ \\ ${ }^{1}$ Cukurova University, Turkey. \\ ${ }^{2}$ İstanbul Technical University, Turkey.
}

\begin{abstract}
Soil erosion causes loss of soil nutrients, decline in crop yields, and reduction in soil productivity. Moreover, soil moved by erosion carries nutrients, pesticides and other harmful farm chemicals into rivers, streams, and ground water resources. Subsequently, protecting soils from erosion is important to sustain landscapes and human life. Geographic Information Systems (GIS) have emerged as a powerful tool for handling spatial information and interact well with erosion models to provide robust problem solving capabilities useful for effective decision making. Erosion models often require moderate to high amounts of spatial data, which can be effectively handled through GIS. The Universal Soil Loss Equation (USLE), later Revised (RUSLE), is a relatively simple model that has remained one of the most practical methods for estimating soil erosion potential and the effects of different management practices for over 40 years. Coupling GIS and RUSLE has been shown in many cases to be an effective approach for estimating the magnitude of soil loss and identifying spatial locations vulnerable to soil erosion. The objective of this research was to develop a user-friendly GIS-based application that could quickly estimate soil loss in Büyük Menderes, which is a Mediterranean River Basin through the integration of GIS and erosion modelling. RUSLE was chosen to model erosion due to its simplicity, wide acceptance/use, and manageable data requirements. This study emphasizes that spatial information technology including, remote sensing and GIS with RUSLE erosion modelling approach could be utilized in the spatial and quantitative assessment of erosion risk. The study showed that $2 \%$ of the basin is subject to very high erosion risk, $11 \%$ has high erosion risk, $33 \%$ has medium erosion risk. This erosion risk assessment also pointed the hot spot areas of erosion to related authorities to help in their erosion prevention efforts.
\end{abstract}

Keywords: Büyük Menderes Basin, erosion, GIS, RUSLE, Mediterranean.

\section{INTRODUCTION}

Soil is one of the most important natural resources due to its physical, biological and chemical functions; it has a major environmental role. Its structure and fabric are modified by various natural processes, among which soil erosion is the foremost [1]. Human activities are generally responsible for accelerating this process, until the potential productivity of soil and its fertility are significantly reduced.

Soil erosion causes loss of soil nutrients, decline in crop yields, and reduction in soil productivity. Moreover, soil moved by erosion carries nutrients, pesticides and other harmful farm chemicals into rivers, streams, and ground water resources. Subsequently, protecting soils from erosion is important to sustain human life. Finally, soil erosion causes air pollution through emissions of radioactive gases such as carbon dioxide $\left(\mathrm{CO}_{2}\right)$, methane $\left(\mathrm{CH}_{4}\right)$, and nitrous oxide $\left(\mathrm{N}_{2} \mathrm{O}\right)[2]$. 
Accelerated soil erosion is a serious problem worldwide, with unpredictable economic and environmental impacts because of its extent, magnitude, rate, and complex processes. Numerous human-induced activities, such as mining, construction, and agricultural activities, disturb land surfaces, resulting in erosion. Soil erosion from cultivated areas is typically higher than that from uncultivated areas. Soil erosion can pose a great concern to the environment because cultivated areas can act as a pathway for transporting nutrients, especially phosphorus attached to sediment particles of river systems.

Geographic Information Systems (GIS) have emerged as a powerful tool for handling spatial information and interact well with erosion models to provide robust problem solving capabilities useful for effective decision making. Erosion models are helpful for evaluating the impact of land-use practices on soil losses, and are increasingly being used for establishing guidelines and standards for regulation purposes [3].

Erosion models often require moderate to high amount of spatial data, which can be effectively handled through GIS. The Universal Soil Loss Equation (USLE), later Revised (RUSLE), is a relatively simple model that has remained one of the most practical methods for estimating soil erosion potential and the effects of different management practices for over 40 years.

Coupling GIS and RUSLE has been shown in many cases to be an effective approach for estimating the magnitude of soil loss and identifying spatial locations vulnerable to soil erosion. The objective of this research was to develop a user-friendly GIS-based application that could quickly estimate soil loss in Büyük Menderes River Basin (BMRB) through the integration of GIS and erosion modelling. RUSLE was chosen to model erosion due to its simplicity, wide acceptance/use, and manageable data requirements.

BMRB is located at the west part of Anatolia. BMRB is the water collection area of the river of Büyük Menderes, which is the longest river in the Aegean region. The basin has a total drainage area of $26,000 \mathrm{~km}^{2}$ which is the $3.2 \%$ of Turkey coverage. The river valley is extremely fertile; thus, the major activity in the basin is agriculture. Three major cities of the Aegean Turkey, namely Aydin, Denizli and Uşak are located in the region to account for a population of more than 2.1 million.

BMRB is productive not only in terms of agriculture but also in industry and tourism. These activities indicate significant attraction for the migration of population. Rapid population growth in last decades caused rapid change in land use/cover change from natural to anthropogenic areas. This process accelerated with the global phenomena like climate change and resulted in regional scale ecological risk issues of erosion.

\section{METHOD}

\subsection{Study area}

$\mathrm{BMRB}$ is located between $37^{\circ} 12-38^{\circ} 40^{\prime}$ north latitudes and $27^{\circ} 15-30^{\circ} 15^{\prime}$ 'west longitudes in the southwestern part of Turkey in Western Anatolia. BMRB which constitutes $3.2 \%$ of the surface area of Turkey, consists lands from the provinces of Denizli, Aydın, Uşak, Afyon, Muğla, İzmir, Isparta, Burdur, Kütahya and Manisa (Fig. 1).

Elevation in the basin is ranged between 0 and $2500 \mathrm{~m}$, and under this variable elevation, the basin has a rugged structure that the slope can increase up to $74^{\circ}$. Despite the Basin's rugged topography, it is considered intensive agricultural practices due to fertile soil. These agricultural activities that are mostly prominent as improper land-use selection have increased the erosion by converting the natural vegetation to agricultural lands on sloped regions. 


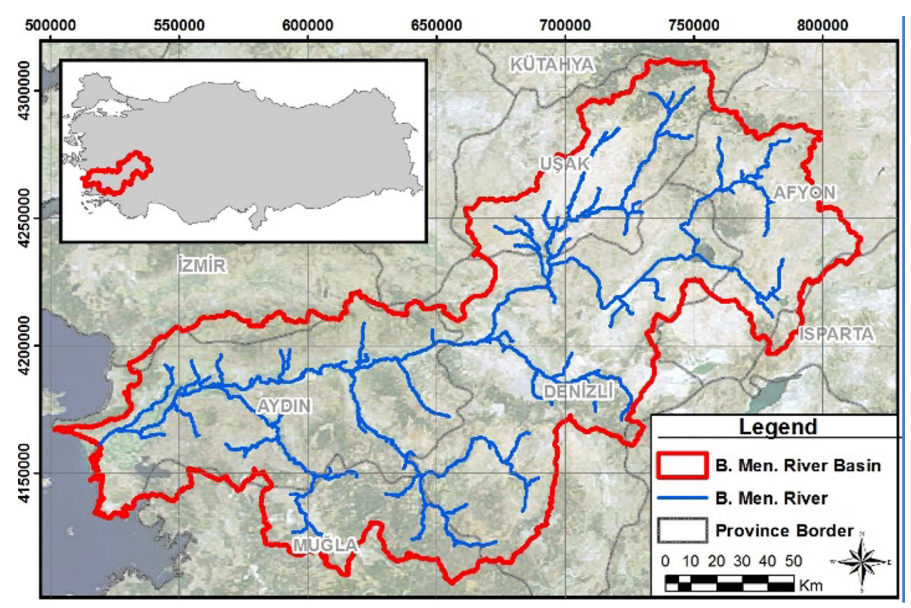

Figure 1: Study area.

\subsection{Materials}

Basic materials to be used within the scope of erosion modelling are the data of topography, soil, climate and land cover.

- LANDSAT satellite images: Fifteen LANDSAT images were provided from three frames and three dates, which represent varied vegetation periods of a season for land cover classification and Normalized Difference Vegetation Index (NDVI) production.

- Digital Elevation Model (DEM): Eight frames of ASTER GDEM is obtained from ASTER project web achieve database which have spatial resolution of 30 meters. The frames were mosaicked and extracted according to basin borders.

- Precipitation Data: Monthly rainfall data to be used in the calculation of rain intensity was obtained from the General Directorate of Turkish State Meteorological Service. The meteorology station-based daily rainfall data between years of 2010 and 2015 were summed and averaged per month. This data per station were interpolated by kriging, which resulted as monthly average total precipitation surface data.

- Soil Data: Soil erodibility data were interpolated using kriging from database of "Soil Erodibility Values of Turkish Soil Classes" Project which is managed by Turkish Ministry of Food, Agriculture and Livestock.

\subsection{Method}

Based on the data assembled at the National Runoff and Soil Loss Data Center of U.S. Department of Agriculture and previous studies, Wischmeier and Smith, and others developed the USLE in 1965 and revised it in 1978 [4]. RUSLE the revised version of USLE is an empirical soil erosion equation, which is not only predicting erosion rates of ungauged watersheds using knowledge of the watershed characteristics and local hydroclimatic conditions [5], but also presents the spatial heterogeneity of soil erosion [6]. In this study, the 
mean annual gross soil erosion was calculated at a cell level in a GIS environment using six factors eqn (1).

$$
A=R \times K \times L \times S \times C \times P
$$

Where;
A : average annual soil loss $\left(\right.$ ton $\left.\cdot \mathrm{ha}^{-1} \cdot \mathrm{year}^{-1}\right)$;
$\mathrm{R} \quad$ : climatic factor or rainfall erosivity index $\left(\mathrm{MJ} \cdot \mathrm{mm} \cdot \mathrm{ha}^{-1} \cdot \mathrm{h}^{-1} \cdot \mathrm{year}^{-1}\right)$;
$\mathrm{K} \quad$ : soil erodibility factor (ton $\cdot \mathrm{ha} \cdot \mathrm{h} \cdot \mathrm{ha} \mathrm{a}^{-1} \cdot \mathrm{MJ}^{-1} \cdot \mathrm{mm}^{-1}$ );
$\mathrm{L} \quad$ : topographic factor of slope length;
S : topographic factor of slope steepness;
C : crop/vegetation cover and management factor;
$\mathrm{P} \quad$ : conservation or support practice factor.

The RUSLE factors were calculated and mapped by using most widespread and effective methods per factor listed below with the help of remote sensing and GIS techniques from proper input data of climate stations, soil maps and reports, DEM and satellite images (Fig. 2).

- Rainfall erosivity (R) factor, which is defined as the aggressiveness of the rain to cause erosion is calculated eqn (2) where $p_{i}$ is mean monthly precipitation and $P$ is mean annual precipitation [4].

$$
R=\sum_{i=1}^{12} 1.735 \times 10^{1.5 \operatorname{Logpi}^{2} / P-0.8188}
$$

- Soil erodibility (K) factor which is the resistance of soil against disruption, transportation and erosion is extracted as direct $\mathrm{K}$ factor value from database of "Soil Erodibility Values of Turkish Soil Classes" project which is managed by Turkish Ministry of Food, Agriculture and Livestock and interpolated by kriging method and mapped as surface data.

- Slope Length (L) and Slope Steepness (S) factors reflect the effect of topography on erosion. The slope length factor $(\mathrm{L})$ represents the effect of slope length on erosion, and the slope steepness factor $(S)$ reflects the influence of slope gradient on erosion. $L$ and $S$ factors were calculated by eqns (3)-(5) [7] where $\lambda$ is slope length as meter and $\theta$ is slope as degree which were calculated from DEM data.

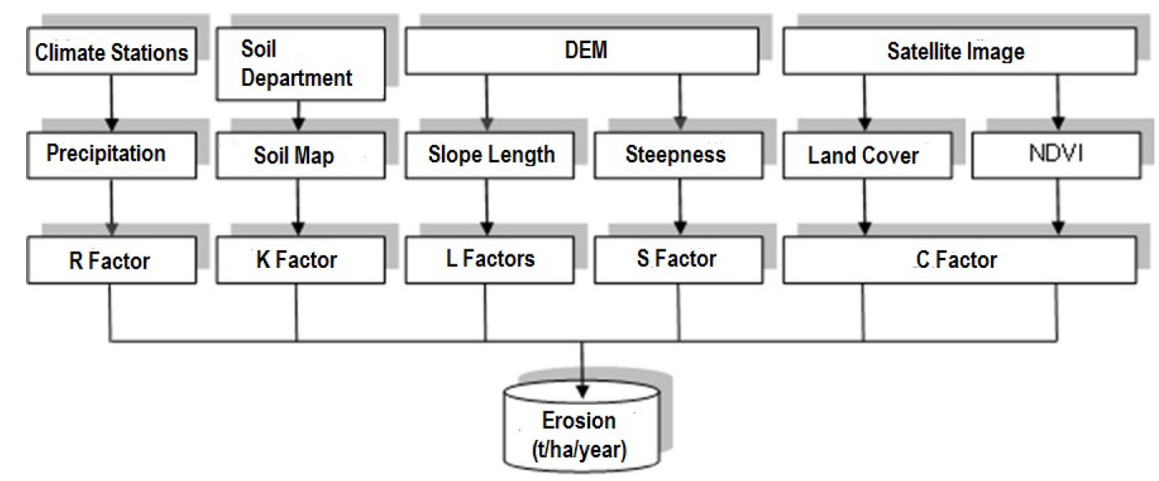

Figure 2: Workflow of method. 


$$
\begin{aligned}
& S=10.8 \sin \theta+0.03 \quad(\text { Slope }<\% 9) \\
& S=16.8 \sin \theta-0.03 \quad \text { (Slope } \geq \% 9 \text { ) } \\
& \mathrm{L}=(\lambda / 22.12)^{m} \quad m=\beta /(1+\beta) \quad \beta=(\operatorname{Sin} \theta / 0.0896) /\left(3.0(\operatorname{Sin} \theta)^{0.8}+0.56\right)
\end{aligned}
$$

- Vegetation Cover (C) Factor is used to reflect the effect of cropping and management practices on soil erosion rates in agricultural lands and the effects of vegetation canopy and ground covers on reducing soil erosion in forested regions. The basic and the most effective eqn (6) which is based on NDVI as input was used to calculate $\mathrm{C}$ factor $[8,9]$.

$$
C=e^{(-a(N D V I /(\beta-N D V I)))}
$$

Where $\alpha$ and $\beta$ are unitless parameters that determine the shape of the curve relating to NDVI and the C factor. NDVI is a numerical indicator that uses the visible and nearinfrared bands of the electromagnetic spectrum, and is adopted to analyze remote sensing measurements and assess whether the target being observed contains live green vegetation or not.

- Conservation or Support Practice (P) Factor is the ratio of soil loss with a specific support practice to the corresponding loss with upslope and downslope tillage. The P factor was taken as " 1 " because the lack of regular data of conservation and support activities in the basin.

\section{RESULTS}

Using eqn (1), the average annual soil loss in the BMRB was computed by overlaying the factor grids into a result grid under GIS environment, with a uniform spatial resolution of 30 $\mathrm{m}$. As a first step of method using interpolated 43 climate stations monthly and annual precipitation grids in eqn (2), the average annual rainfall erosivity (R) factor from 2010 to 2015 was calculated (Fig. 3). $\mathrm{R}$ factor values are reaching the highest value at the south part of the basin while declining towards the rest of the basin which is excessive towards the north and east.

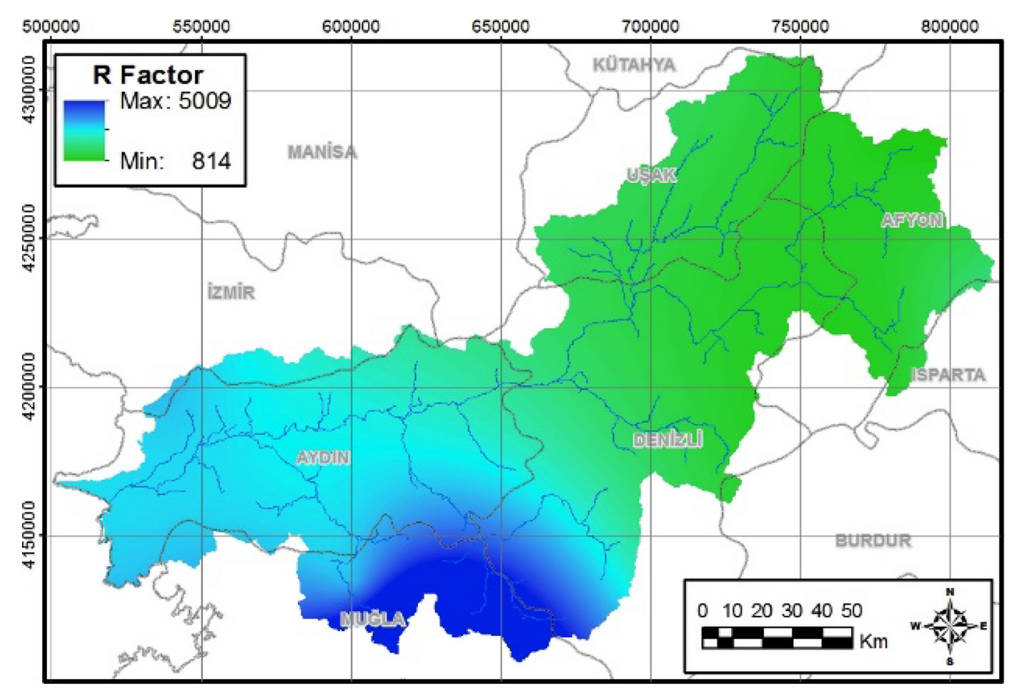

Figure 3: Rainfall erosivity (R) factor. 
Soil erodibility grids were interpolated by using kriging over 155 locations (60 in and 95 by the max $25 \mathrm{~km}$ side of basin) which were extracted from database of "Soil Erodibility Values of Turkish Soil Classes" Project which is managed by Turkish Ministry of Food, Agriculture and Livestock (Fig. 4). As a result average $\mathrm{K}$ factor value is 0.025 while the maximum is 0.063 and minimum is 0.007 across the basin. Additionally, $\mathrm{K}$ factor value varies within the basin; some regions at the central southern and northwest parts of the basin represent higher values while eastern and central northern part of the Basin, have low $\mathrm{K}$ factor values.

Slope Length (L) and Slope Steepness (S) factors were calculated given eqns (3)-(5) using DEM based elevation and slope grids as input (Fig. 5). L factor values are close to average and each other over the basin except the river bed environments and its neighborhood, which have smaller L factor values. Similarly S factor values are smaller at the river bed environments and its neighborhood however the rest of the basin have values close to average except the regions of central and central northern of the basin whose $\mathrm{S}$ factor values remain high.

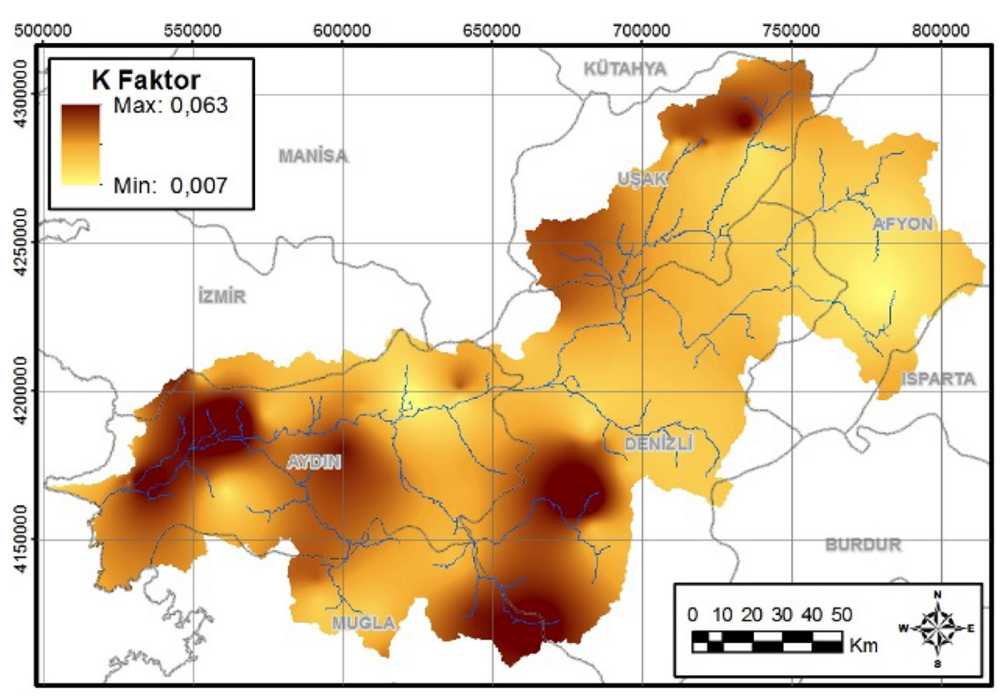

Figure 4: Soil erodibility (K) factor.
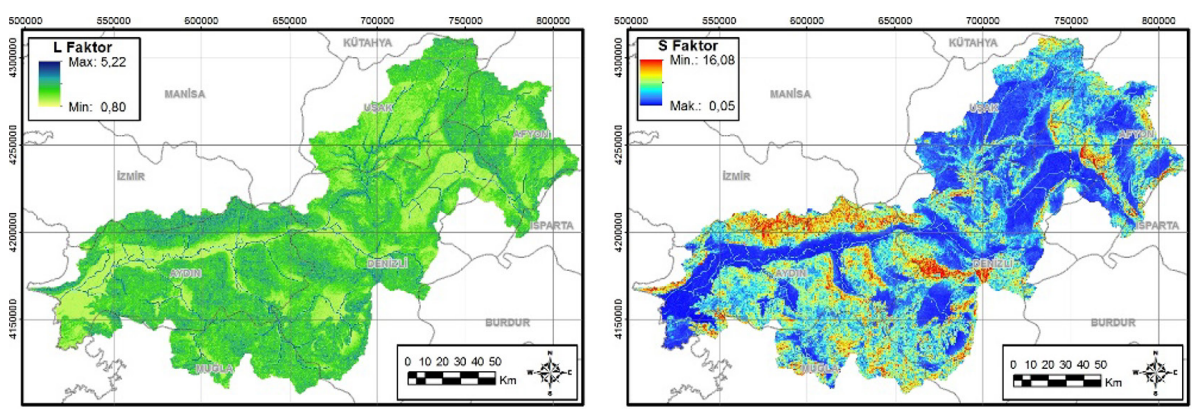

Figure 5: Slope length (L) and slope steepness (S) factors. 
After the calculation of NDVI per five date on LANDSAT images the resulted grids were averaged to find out the mean NDVI for a vegetation year. The mean NDVI value is 0.15 and the min. and max. are -0.77 and 0.74 respectively. Vegetation Cover (C) Factor was calculated using mean NDVI grid of basin with the help of eqn (6) (Fig. 6).

Finally, soil erosion in BMRB is calculated with multiplying the overlayed RUSLE factor under GIS environment, which extracted non-soil areas like water, rocky, etc. and indicate the long-term average annual rate of erosion depending on rainfall pattern, soil type, topography, crop system, and management practices (Fig. 7). RUSLE calculated the annual average soil

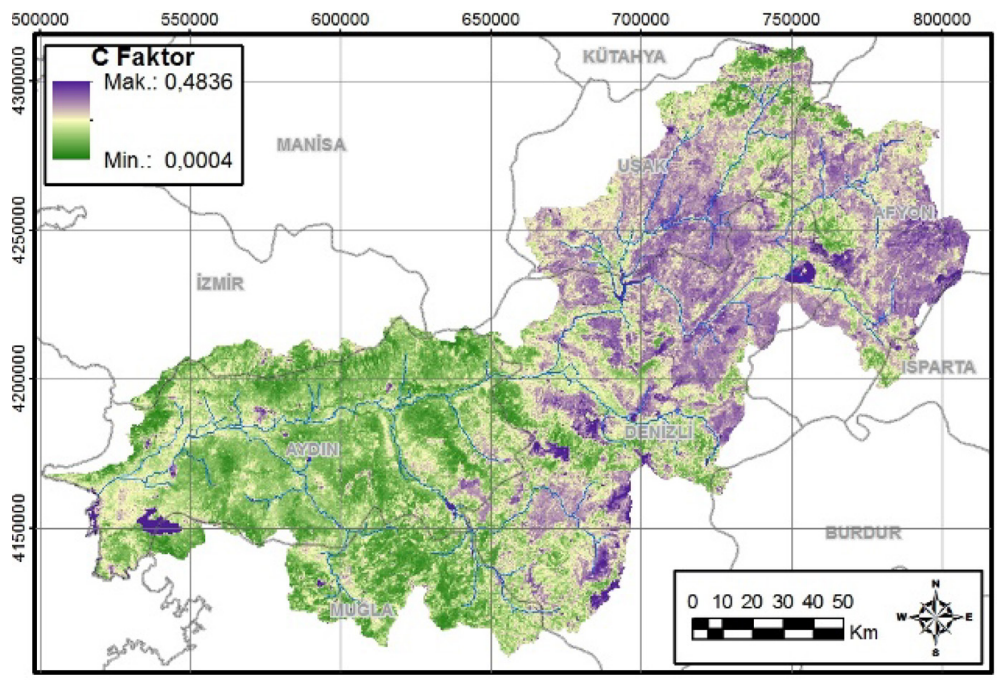

Figure 6: Vegetation cover (C) factor.

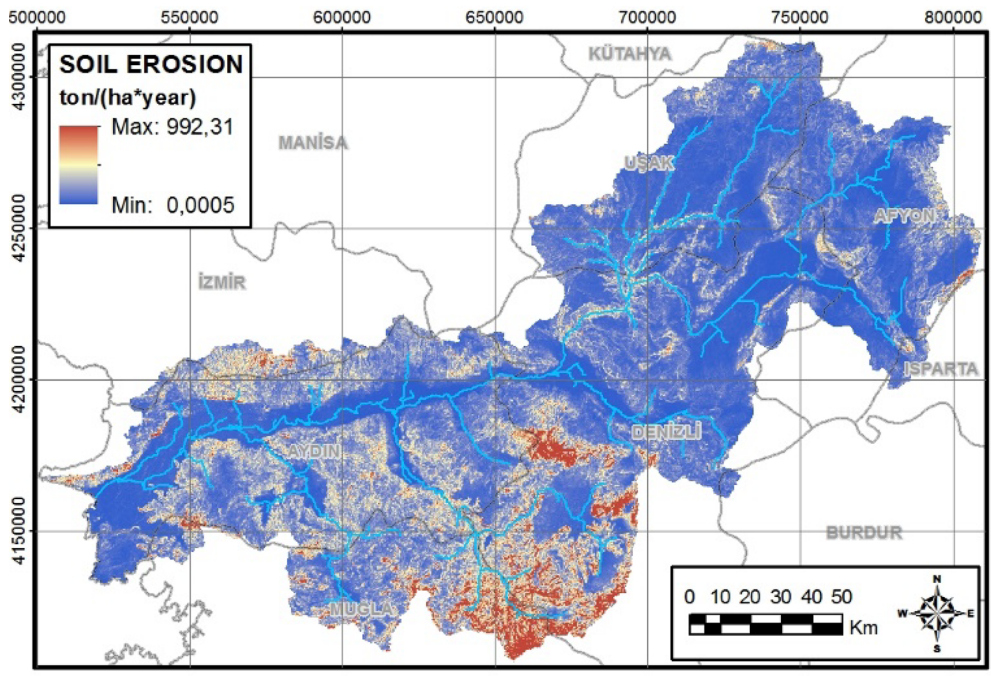

Figure 7: RUSLE erosion estimation map. 


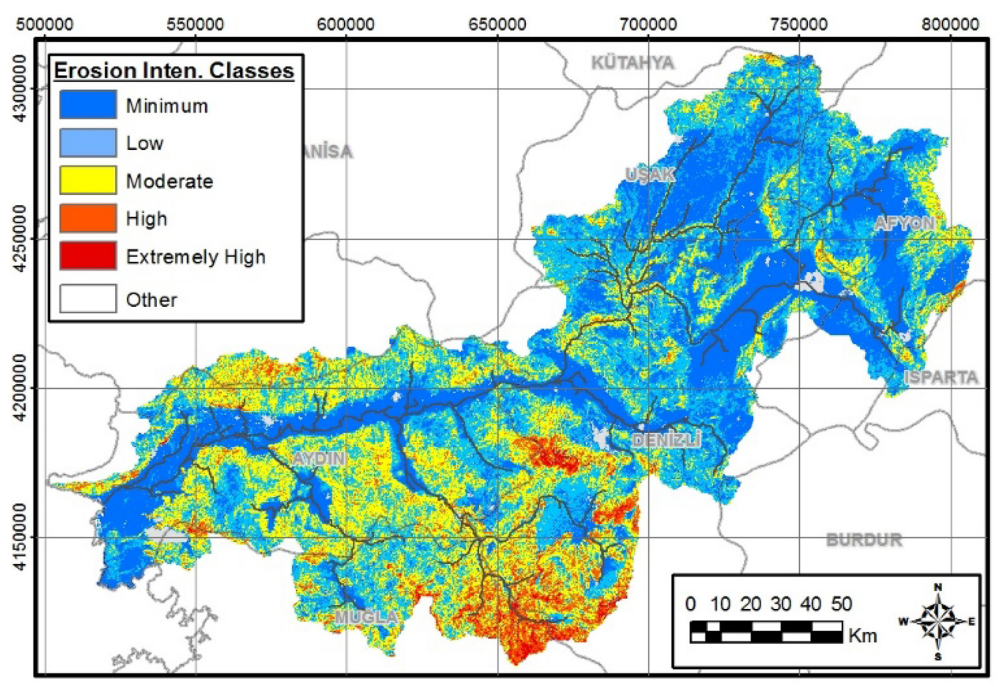

Figure 8: RUSLE erosion intension classes.

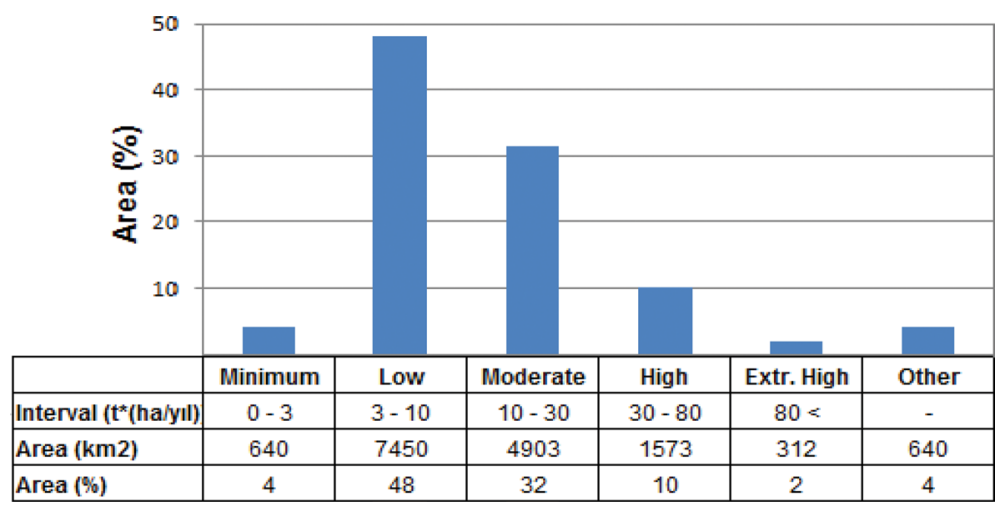

Figure 9: Statistics of erosion intension classes

erosion for the BMRB as 9.9 ton per hectare meanwhile the standard deviation is 19.3 ton/ha per year. Also the soil loss ranges from 0 to 992 ton per hectare per year.

The resulted soil erosion values were scaled to five erosion intension classes using the thresholds were introduced by Wishmeier and Smith [4], Millward and Mersey [10] and Renard et al. [6] (Figs 8 and 9).

The scaled classes represent that the half of the basin is taking place in low, $32 \%$ is in moderate and $12 \%$ is in high and extremely high erosion classes. Basin is covered by $4 \%$ of non-soil areas like water, settlement, rock, etc. which are considered as other class.

\section{CONCLUSION}

Due to the typical rugged topography and especially agriculture-based long-term anthropogenic influences soil erosion is a serious problem in the BMRB. Assessment of soil erosion 
and its spatial distribution at watershed scale also an indicator of erosion risk scale is necessary for sustainable land use and comprehensive soil conservation management.

The process of RUSLE method for a Mediterranean River basin of Turkey with integration of remote sensing techniques and with the help of GIS, pointed the risky erosion hot spot areas to related authorities to help in their erosion prevention efforts. This assessment also show up that the RUSLE method which was used to estimate spatial based erosion, do not only calculate soil loss also represent the erosion risky locations. Which that output grid map of RUSLE with the support of RS and GIS also can be used as a scale of erosion risk spatially.

\section{REFERENCES}

[1] Lal, R. \& Pierce, F.J., The vanishing resource. In Soil Management for Sustainability, Soil and Water Conservation Society, pp. 1-5, 1991.

[2] Larson, D., Natural Resource Assessment and Policy, Soil Managementfor Sustainability, Soil and Water Conservation Society, 1993.

[3] Petter, P., GIS and Remote Sensing for Soil Erosion Studies in Semi-arid Environments, PhD Thesis, University of Lund, Lund, 1992.

[4] Wishmeier, W.H. \& Smith, D.D., Predicting Rainfall Erosion Losses: a Guide to Conservation Planning, USDA Agricultural Handbook: Washington, DC, USA, 1978.

[5] Angima, A.D., Stott, D.E., O’Nell, M.K., Ong, C.K. \& Weesies, G.A., Soil erosion prediction using RUSLE for central Kenyan highland conditions. Agriculture Ecosystems and Environment, 97, pp. 295-308, 2003.

http://dx.doi.org/10.1016/S0167-8809(03)00011-2

[6] Renard, K.G., Foster, G.R., Weesies, G.A., McCool, D.K. \& Yoder, D.C., Predicting Soil Erosion by Water: A guide to conservation planning with the Revised Universal Soil Loss Equation (RUSLE), Agriculture Handbook: USDA, Washington, USA., 703, 1997.

[7] Van Remortel, R., Hamilton, M. \& Hickey, R., Estimating the LS factor for RUSLE through iterative slope length processing of digital elevation data. Cartography, $\mathbf{3 0}$, pp. 27-35, 2001. http://dx.doi.org/10.1080/00690805.2001.9714133

[8] Van der Knijff, J.M., Jones, R.J.A. \& Montanarella, L., Soil erosion risk assessment in Europe, EUR 19044 EN, Office for Official Publications of the European Communities, Luxembourg, 2000.

[9] Van Leeuwen, W.J.D. \& Sammons, G., Vegetation dynamics and soil erosion modeling using remotely sensed data (MODIS) and GIS. Tenth Biennial USDA Forest Service Remote Sensing Applications Conference, 5-9 April 2004, UT. US Department of Agriculture Forest Service Remote Sensing Applications Center, Salt Lake City, 2004.

[10] Millward, A. \& Mersey, J., Adapting the RUSLE to model soil erosion potential in a mountainous tropical watershed. Catena, 38, 1999.

http://dx.doi.org/10.1016/s0341-8162(99)00067-3 